\title{
Formação de Professores e Ensino de Química: Reflexões a partir do Livro Serões de Dona Benta de Monteiro Lobato e da Pedagogia de Paulo Freire
}

(Teacher Education and Chemistry Teaching: Reflections on the Book Serões de Dona Benta by Monteiro Lobato and the Pedagogy of Paulo Freire)

\section{MARCELO PIMENTEL DA SILVEIRA ${ }^{1}$ e JOÃO ZANETIC ${ }^{2}$}

${ }^{1}$ Universidade Estadual de Maringá (martzelops@gmail.com)

${ }^{2}$ Universidade de São Paulo (zanetic@if.usp.br)

Resumo. O trabalho discute a veia pedagógica de Monteiro Lobato, a partir da leitura da sua obra infantil, particularmente os Serões de Dona Benta, buscando identificar trechos onde apareciam abordagens específicas de conhecimentos químicos interpretados à luz da pedagogia de Paulo Freire, com destaque às noções de pedagogia da pergunta, curiosidade epistemológica e saberes necessários à formação de um professor crítico e reflexivo, na perspectiva de evidenciar as contribuições que as relações entre literatura e ciências podem trazer para o ensino da química. Nossa análise expõe que a ciência apresentada por Dona Benta exemplifica um professor que vai além de uma discussão estritamente centrada na especificidade da ciência ou dos conceitos químicos, por meio da pedagogia da pergunta, revelando que os Serões apresentam um potencial para problematizar questões a respeito da prática docente. Dona Benta, por exemplo, deixa evidente que formar não é treinar; ensinar não é transferir conteúdos e utiliza o diálogo, a problematização e a curiosidade como opção metodológica.

Abstract. This work discusses the pedagogical style of Monteiro Lobato, based on the reading of his body of children's literature, especially Serões de Dona Benta, with the aim of identifying excerpts where specific approaches to chemistry knowledge appear in the light of the pedagogy of Paulo Freire. The notions of question-asking pedagogy, epistemological curiosity and knowledge necessary for the education of a critical and reflective teacher are highlighted, with a view to showing the contributions that the relationships between literature and sciences can bring to chemistry teaching. Our analysis states that the science presented by Dona Benta exemplifies a teacher that goes beyond a discussion that is strictly centered on the specificity of science or concepts of chemistry. This is done by means of question-asking pedagogy, revealing that Serões de Dona Benta presents a potential that can be used to problematize questions as regards teaching practice. Dona Benta, for example, makes clear that educating is not training and teaching is not only transferring content. She uses dialog and problematization of the doubt and curiosity as a methodological option.

Palavras-chave: literatura, curiosidade, ensino de química, pergunta

Keywords: literature, curiosity, chemistry teaching, question

\section{Introdução}

Desde o final da década de 1990, pesquisadores em ensino de ciências no Brasil vêm dando destaque à importância da leitura no processo de ensino e aprendizagem em ciências. Almeida e Silva (1998) ressaltam que as relações entre leitura, literatura e produção científica ganharam força como uma linha de pesquisa, principalmente no contexto do ensino da Física, com a produção de propostas que visam promover uma formação mais humanística.

Zanetic (1998) tece vários argumentos relacionados à ideia do cientista com veia literária e do escritor com veia científica. Os escritores incluídos na segunda categoria são aqueles que: “com menor ou maior conhecimento das grandes sínteses científicas e 
suas implicações, produziram obras literárias utilizando tal conhecimento tanto como fonte inspiradora do conteúdo quanto como guia metodológico/filosófico" (ZANETIC, 1998, p. 13-14).

Zanetic (2006) dá alguns exemplos de escritores com veia cientifica, mencionando: Edgar Allan Poe, Emile Zola, Fiodor Dostoiévski, Julio Verne, Herbert G. Wells, Monteiro Lobato, Bertolt Brecht, Arthur Koestler, Primo Levi e Italo Calvino. Boa parte dos escritores dessa categoria tem alguma relação com a ciência, por exemplo: H.G. Wells, era biólogo e escreveu até uma Enciclopédia de História Natural; Edgar Allan Poe foi jornalista e escrevia resenhas de livros científicos; Dostoiévski se formou em engenharia militar e Primo Levi foi químico de formação e atuação profissional (ZANETIC, 1998).

À luz do que vem sendo pesquisado a respeito das relações entre ciência e literatura, consideramos que três aspectos podem ser destacados como contribuições que essas relações podem trazer para o ensino, aprendizagem e formação de professores dedicados à educação científica: a imaginação comum ao cientista e ao artista, a arte como instrumento para humanizar o ensino da ciência e os escritores com veia científica que incorporam essas e outras características em suas obras (SILVEIRA, 2013).

Existe ainda um número reduzido de trabalhos relacionados ao papel desempenhado pela leitura de textos literários na formação de professores de química, embora as Diretrizes Curriculares Nacionais para os Cursos de Química (DCNQ) sinalizem uma formação de professor que consiga fazer uma leitura inteligente do mundo de forma a ser capaz:

[...] de assimilar os novos conhecimentos científicos e/ou educacionais e refletir sobre o comportamento ético que a sociedade espera de sua atuação e de suas relações com o contexto cultural, socioeconômico e político; ter formação humanística que permita exercer plenamente sua cidadania e, enquanto profissional, respeitar o direito à vida e ao bem estar dos cidadãos; assumir conscientemente a tarefa educativa, cumprindo o papel social de preparar os alunos para o exercício consciente da cidadania (BRASIL, 2001, p. 6-8).

O licenciando em química necessita dos conhecimentos técnicos e teóricos da química como base principal para subsidiar o diálogo com o mundo atual, no sentido de ser capaz de "aprender a "ler" o mundo, aprender a questionar as situações, sistematizar problemas e buscar criativamente soluções" (BRASIL, 2001, p. 2). No entanto, consideramos que apenas os conhecimentos científicos específicos não bastam para "ler" o mundo e a complexidade que envolve o ser humano e a realidade, sendo 
necessária a inserção de uma formação mais humanística na preparação do futuro professor. No âmbito do ensino de química destacamos os trabalhos de Porto (2000; 2007), Pinto Neto (2001; 2004; 2008), Silva (2011) e Gonçalves (2014) que enfatizam as possíveis contribuições da literatura para o ensino dessa ciência.

Porto (2000) promove uma reflexão sobre o potencial de relações interdisciplinares a partir da leitura e problematização do poema Psicologia de um Vencido de Augusto dos Anjos. Porto et al. (2007) discutem a utilização do capítulo Potássio, do livro A Tabela Periódica de Primo Levi, como tema inicial para abordar conceitos químicos com alunos da graduação na perspectiva de provocar os estudantes na busca de soluções de problemas por meio das questões levantadas sobre a leitura do capítulo citado.

Pinto Neto (2001) realizou um estudo sobre representações de ciência e fazer ciência em romances produzidos no Brasil entre o final do século XIX e início do século XX. Também orientou a dissertação de mestrado Memórias do Visconde de Sabugosa (PEREIRA, 2006), assim como publicou dois interessantes artigos: Júlio Verne: o propagandista das ciências (PINTO NETO, 2004) e A Química segundo Primo Levi (PINTO NETO, 2008).

Silva (2011) discute o potencial do uso da poesia Lágrima de Preta, de Antonio Gedeão ${ }^{1}$, nas aulas de química e ressalta a contribuição dessa poesia para a "formação de professores críticos, autônomos, versáteis que entendam o conhecimento científico como uma das muitas formas de conhecimento, que está presente em diversos contextos" (SILVA, 2011, p. 84).

Gonçalves (2014) problematiza A Tabela Periódica de Primo Levi, destacando seu potencial como forma de abordar a experimentação na formação de professores de química, uma vez que pode "apontar aos futuros docentes maneiras de colaborar para um processo interdisciplinar na educação básica e para a promoção da leitura de modo a vislumbrar uma formação cultural mais ampla aos estudantes de diferentes níveis de ensino" (GONÇALVES, 2014, p 93).

Diante das contribuições que a relação entre ciência e literatura pode trazer ao ensino de química, neste artigo discutimos a respeito da utilização do diálogo e da curiosidade na aprendizagem de conhecimentos científicos e as possibilidades que o

\footnotetext{
${ }^{1}$ Antônio Gedeão é o nome artístico do professor de física e poeta português Rómulo de Carvalho (19061997) que escreveu inúmeras poesias inspiradas em temas científicos.
} 
texto de Monteiro Lobato apresenta para promover reflexões sobre questões referentes à prática docente e a formação de professores de química.

Monteiro Lobato sempre apresentou interesse pela ciência, incorporando-a em sua produção literária. Em sua obra infantil podemos notar sua veia científica, tanto que existem vários estudos a respeito da ciência e sobre a preocupação com o saber e inteligência das crianças em seus livros (SCAVONE, 1981; CAMENIETZKI, 1988; APÓSTOLO NETTO, 1996; CARVALHO, 2002; PEREIRA, 2006; SANTOS, 2008; SANTOS, 2011 e OLIVEIRA, 2011).

Groto (2012) e Groto e Martins (2015a) estudaram a aproximação entre literatura e ensino de ciências por meio da utilização dos livros A Reforma da Natureza e Serões de Dona Benta em aulas de Ciências e de Língua Portuguesa, revelando o potencial que os livros apresentaram para promover o diálogo em sala de aula, assim como a possibilidade de contextualizar e problematizar os conteúdos científicos presentes nas estórias. Os autores também estudaram os livros Reinações de Narizinho, A reforma da natureza e $A$ chave do tamanho, indicando o potencial dos mesmos para problematizar questões a respeito da natureza da ciência em aulas de Ciências do Ensino Fundamental.

A escolha de Monteiro Lobato ocorreu, então, porque a ciência está presente na sua obra infantil e adulta como também em crônicas, artigos e traduções das mais variadas formas, corroborando a hipótese de Monteiro Lobato como "escritor com veia científica" (ZANETIC, 1998, p. 14). A crença na ciência como instrumento para promover o progresso e a melhoria da qualidade de vida das pessoas é incorporada em sua obra.

Em nossa pesquisa, durante a leitura de Serões de Dona Benta, A Chave do Tamanho, A Reforma da Natureza, Viagem ao Céu, O Minotauro, O Poço do Visconde, Reinações de Narizinho, Aritmética da Emília, Emília no País da Gramática, História do Mundo para as Crianças, Dom Quixote das Crianças, Caçadas de Pedrinho, O Saci, Os Doze Trabalhos de Hércules $1^{\circ}$ e $2^{\circ}$ Tomos, Memórias da Emília, História das Invenções e Geografia de Dona Benta ${ }^{2}$, procuramos identificar trechos nos quais Dona Benta estivesse, direta ou indiretamente, envolvida com a ciência, com o conhecimento científico e a química. Neste artigo nos restringimos ao potencial pedagógico com base nos Serões de Dona Benta.

\footnotetext{
${ }^{2}$ Os livros não foram necessariamente lidos na ordem apresentada.
} 
Desta forma, buscamos identificar nos livros, trechos selecionados a partir de situações onde apareciam abordagens específicas de conhecimentos químicos, por exemplo, a descoberta do oxigênio, discussões sobre a água, o seu uso e suas propriedades. Nos trechos relacionados à química foi possível identificar a curiosidade e a pergunta como eixos condutores das abordagens didáticas.

A veia pedagógica de Monteiro Lobato foi analisada, utilizando a pedagogia de Paulo Freire como principal referência teórica. O papel da curiosidade, da pergunta e do diálogo nas situações de ensino e aprendizagem, presentes na obra infantil de Monteiro Lobato, permitem uma aproximação entre o escritor e Paulo Freire, no sentido de mostrar que ambos defendiam a "curiosidade epistemológica" como forma de manter o interesse na busca pelo conhecimento, por meio do diálogo e de uma pedagogia da pergunta. Destacamos a aproximação de Serões de Dona Benta com os saberes apontados por Paulo Freire no livro Pedagogia da Autonomia como necessários na formação de um professor crítico, por exemplo, formar não é treinar; ensinar não é apenas transferir conteúdos; ensinar exige curiosidade e o professor deve saber perguntar.

A leitura de textos literários deve estar presente na formação inicial de professores, pois, além de estimular a leitura, a literatura permite aos leitores a vivência com situações que transcendem o conhecimento científico, mostrando a ciência como uma construção humana, fruto do estudo, da inventividade, da imaginação e da criatividade do ser humano. Mas como abordar questões culturais, históricas, filosóficas e sociais em cursos com características predominantemente de ciências exatas?

De acordo com Pinto Neto (2008) existe a necessidade de uma formação cultural mais ampla dos futuros professores de química a partir do acesso a uma variedade de fontes da produção do conhecimento humano, fazendo destaque especial à literatura como uma alternativa, uma vez que o:

[...] processo de formação de professores, visto como o conjunto de experiências que são proporcionadas aos licenciandos, é também o lugar de uma formação cultural mais ampla, na qual o futuro professor toma contato com diferentes formas de ver, pensar e representar o mundo. Sendo que ao final do processo será este conjunto de experiências, de cunho estético, moral, ético e cultural que irão compor a "bagagem do professor" (PINTO NETO, 2008, p.01).

Certamente é um desafio para a formação de professores de química, suscitando a busca de abordagens mais interdisciplinares que têm na leitura de textos literários um 
dos caminhos alternativos para buscar resposta à questão levantada. Pensando nesse desafio investigamos o potencial pedagógico da obra de Monteiro Lobato para o ensino de química.

Neste artigo, apresentamos as discussões a respeito do diálogo e do uso da curiosidade como forma de provocar a aprendizagem de conhecimentos científicos, buscando compreender de que forma o texto de Monteiro Lobato pode promover reflexões sobre questões referentes à prática docente no contexto da formação inicial de professores de química.

\section{Monteiro Lobato}

Monteiro Lobato (18/04/1882 - 04/07/1948) nasceu em Taubaté - interior da então Província de São Paulo - na Fazenda Santa Maria. Filho de José Bento Marcondes Lobato e de Olímpia Augusta Monteiro Lobato e neto do Visconde de Tremembé, desde criança, se encantava pela leitura por meio de visitas à rica e variada biblioteca do avô. Durante os primeiros anos de sua infância convive com o fim dos regimes escravagista e monárquico, presenciando dois momentos políticos importantes para a nação brasileira - o 13 de maio de 1888 e o 15 de novembro de 1889, marcados por uma série de inquietantes problemas que chamavam a atenção dos intelectuais brasileiros.

Apesar de se interessar pela pintura e ter o desejo de estudar na Escola de Belas Artes, acaba atendendo ao "pedido" de seu avô e ingressa em 1900 na Faculdade de Direito da Universidade de São Paulo. De acordo com Cavalheiro (1956a), Monteiro Lobato foi um estudante mediano, com pouco interesse pela área de direito, como disse ele próprio: "Fiz - ato de presença na Academia, no "quantum satis" para obter diploma". Formou-se em dezembro de 1904, "completando o lustro acadêmico com o mesmo desinteresse inicial pelos estudos" (CAVALHEIRO, 1956a, p.58).

Monteiro Lobato, a partir de então sempre atuou em diferentes atividades, foi fazendeiro, editor, escritor, jornalista, adido comercial, empresário no ramo de petróleo, cronista e crítico de arte. Durante toda a sua vida teve a mania dos negócios, mas a sua maior característica, entretanto, sempre foi estar muito à frente de seu tempo:

[...] lançou a exploração de uma indústria livresca, que se tornou possível, exatamente dentro das normas que traçou. Somente 10 anos depois. Ideou uma oficina gráfica também de possível funcionamento daí a 20 anos. Afirmou que existia petróleo no Brasil, muitos anos antes que a sua certeza fosse comprovada. Mostrou a importância do problema metalúrgico com 25 anos de antecedência. Seu projeto de conquistar novos mercados para o café, nos países asiáticos e eslavos, está ainda na ordem do dia. De seu próprio bolso, pagou a químicos americanos as primeiras pesquisas sobre o babaçu, 
que sempre acreditou representar uma das grandes fontes de riqueza para o Brasil [...] (CAVALHEIRO, 1956b, p. 117).

\section{Monteiro Lobato e a veia pedagógica}

Na obra infantil de Monteiro Lobato, tanto nos livros considerados de cunho didático como em todos os outros, com maior ou menor intensidade, percebemos a presença de uma intenção pedagógica. Ele se mantinha "informado a respeito das coisas de seu tempo, era certamente um homem preocupado com o problema da educação. Não fosse ele interessado em pedagogia não teria produzido a obra imensa que deixou" (ALVAREZ, 1982, p. 62).

A predominância de uma preocupação pedagógica na obra infantil de Monteiro Lobato é justificada por muitos pesquisadores em função da amizade do escritor com alguns dos educadores brasileiros considerados precursores do movimento da Escola Nova $^{3}$. Anísio Teixeira, um dos mais próximos ao escritor, deve tê-lo conhecido em Nova York, durante a sua primeira visita aos Estados Unidos em 1927, época em que o escritor atuava como adido comercial no respectivo país (NUNES, 1986).

A amizade entre os dois provavelmente inspirou o caráter didático da obra infantil de Monteiro Lobato. Existia uma grande admiração mútua, registrada em cartas nas quais ambos trocaram, ao longo da amizade, ideais, sentimentos, incertezas e elogios, conforme podemos verificar no trabalho de Vianna e Fraiz (1986). O diálogo sobre a temática educacional pode ser ilustrado nos trechos de cartas entre Anísio e Lobato, respectivamente:

[...] "Dentro de meses saem seus novos livros, o de ciência... É o mundo sem fantasmas, que você está a criar para as crianças. Santo trabalho, meu caro Lobato, o trabalho que enternece a inteligência muito mais que você o possa imaginar. Quando o vejo a procurar com o ferro e o petróleo dar espinha ao nosso invertebrado Brasil econômico e com os seus livros a arejar a inteligência ao meninão brasileiro que se vai erguer nas suas pernas traseiras, fico a sonhar na sua estátua [...]”. (NUNES, 1986, p. 18)

"Eureka! Eureka! Você é o líder! Você é quem há de moldar o plano educacional brasileiro. Só você tem a inteligência bastante clara e aguda para ver dentro do cipoal de coisas engolidas e não digeridas pelos nossos pedagogos reformadores. Acho que antes de reformarem qualquer coisa ou proporem reformas, os mais adiantados e ilustres líderes educacionais do

\footnotetext{
${ }^{3}$ De acordo com Arapiraca (1996, p. 91) o escolanovismo é um "[...] movimento surgido na Europa e Estados Unidos no final do século XIX, como expressão do liberalismo burguês, em sua vertente pragmatista, tendo como alicerces portanto a democracia, a ciência e o trabalho, referências da nova ordem social que se estabelece em decorrência das transformações desencadeadas pela Revolução Industrial, encontra condições especiais para se instalar no Brasil. Os ideários desse movimento consubstanciaram-se no manifesto dos Pioneiros da Escola Nova (1922), assumido por muitos educadores, dentre os quais Fernando de Azevedo, Lourenço Filho e Anísio Teixeira, esse último, grande amigo de Monteiro Lobato".
} 
momento o que devem fazer é reformarem-se a si próprios, isto é, aposentarem-se e saírem do caminho”. (NUNES, 1986, p. 26)

Cabe ressaltar que existe um conjunto de livros em sua obra infantil que são classificados como de caráter predominantemente pedagógico: Emília no país da gramática; Aritmética da Emília; Geografia de Dona Benta; O Poço do Visconde; Serões de Dona Benta; História do mundo para as crianças; História das Invenções. Nesses livros, é possível perceber um projeto pedagógico do autor na medida em que cada disciplina está representada em cada um dos $\operatorname{livros}^{4}$ (DUARTE, 2008; CATINARI, 2006).

Catinari (2006), em seu estudo a respeito da abordagem interdisciplinar presente em A Chave do Tamanho, considera que a intenção pedagógica de Lobato está centrada em uma visão de educação emancipadora. A pesquisadora afirma que é possível identificar no livro aspectos que evidenciam alguns dos principais pressupostos da Escola Nova, tais como a postura crítica do aluno; experimentação e prática; importância dada à arte e ao lúdico no processo de aprendizagem; entre outros.

Arapiraca (1996) destaca a importância em situar a obra de Monteiro Lobato no contexto histórico de seu tempo que foi marcado pelas questões sociais do início do século XX, as duas Grandes Guerras Mundiais e os movimentos artísticos surgidos na Europa. A pesquisadora argumenta que as mudanças educacionais desse período são oriundas dos ideários positivistas e liberais que viam na educação uma forma de preparar o indivíduo para um mundo em plena transformação proporcionada pelo avanço da ciência.

Macedo (1996) realizou um estudo a respeito das interseções entre o pensamento de Jean Piaget e Monteiro Lobato, tecendo discussões sobre as relações entre a ciência e a arte. A pesquisadora defende que o escritor incorporou em seus livros uma linguagem e abordagem que respeitava o estágio de desenvolvimento cognitivo das crianças leitoras de sua obra infantil.

Segundo ela, Monteiro Lobato, de forma análoga a Piaget, percebeu que a criança tem uma forma diferente de pensar em relação ao adulto, sendo necessário abrir espaço para a imaginação e o faz-de-conta no mundo da criança. Escritor e cientista

\footnotetext{
${ }^{4}$ O Poço do Visconde apresenta conhecimentos, principalmente, a respeito da Química, Geologia e Geografia. Serões de Dona Benta apresenta conhecimentos de Ciências (Química, Física, Biologia). O livro Monteiro Lobato, livro a livro: Obra infantil (LAJOLO; CECCANTINI, 2008) apresenta uma coletânea de estudos recentes sobre os livros infantis do escritor, onde é possível analisar vários dos aspectos pedagógicos de sua obra.
} 
valorizam o faz de conta como necessário para a criança construir a sua inteligência por meio do jogo, da brincadeira e do lúdico. A pesquisadora diz que para Piaget a brincadeira é coisa séria e que:

[...] o jogo é o caminho da operacionalidade e, ao desenvolver as estruturas mentais do indivíduo, possibilita o desenvolvimento da inteligência. As histórias de Lobato sugerem a ideia piagetiana: o desafio, a descoberta, as situações-problemas, a curiosidade, as surpresas, fazendo com que as crianças vivenciem uma trama gostosa, uma divertida trajetória pelos caminhos do pensamento e da invenção (MACEDO, 1996, p. 26).

A falta de diálogo nas práticas pedagógicas, assim como a excessiva ênfase dada à memorização mecânica de conceitos, já era, na década de 1930, um problema visualizado por Lobato que, na contramão dos pressupostos da escola de sua época, sonhava com um ambiente de aprendizagem capaz de formar leitores e alunos críticos (CARDOSO, 2008; TEIXEIRA LUIZ, 2008).

A incorporação das intenções pedagógicas na obra infantil de Lobato permite situar o Sítio do Picapau Amarelo como uma espécie de escola ideal com potencial de formar uma criança com pensamento sofisticado ou, como atualmente vem sendo discutido, a formação do cidadão crítico e autônomo intelectualmente.

No Sítio, Dona Benta parece uma professora que trabalha conhecimentos e cultura com as crianças e media o processo de ensino e aprendizagem de forma a viabilizar a aprendizagem de conhecimentos científicos a partir do conhecimento advindo da experiência de cada aluno (SANTOS, 2008; NUNES, 2004). Nesse sentido, Dona Benta representa a liberdade pedagógica proposta pelo escolanovismo, sendo “[...] talvez a figura do professor que o próprio autor pretendia: que soubesse o que ensinar, para quem ensinar e, o mais importante, como ensinar [...]" (NUNES, 2004, p. 220).

A continuidade dos estudos sobre Monteiro Lobato e suas intenções pedagógicas ainda pode ser um campo muito fértil a revelar contribuições para o ser professor e o processo de ensino e aprendizagem. $\mathrm{O}$ escritor com veia pedagógica aborda em seus livros questões ainda atuais e relevantes no âmbito do ensinar e da prática de ensinar.

Os vários aspectos destacados a respeito do interesse e intenção pedagógica de Monteiro Lobato em sua obra infantil, com o diálogo e a problematização como opções metodológicas para promover a aprendizagem e não a memorização dos conhecimentos; a valorização da experimentação como instrumento pedagógico; a preocupação com o uso e as consequências da ciência perante a sociedade; entre outros, nos leva a buscar na 
obra infantil do escritor episódios, exemplos de abordagem e posturas que possam ser problematizadas no contexto da prática docente em química.

\section{Pedagogia da autonomia e a formação de professor}

O educador necessita aprender a criar espaços onde sejam garantidas situações de diálogos com o educando e que envolvam o contexto concreto e o contexto teórico como bases de uma postura pedagógica voltada para a construção de saberes sistematizados. O caminho metodológico em busca da razão de ser do conhecimento pode ser facilitado por meio do diálogo alicerçado em uma pedagogia da pergunta.

De acordo com o filósofo Antonio Faundez todo professor deveria saber ensinar a perguntar, pois a impressão que se tem a respeito do ensino é que o saber é sempre resposta e não há espaço para perguntas. Parece que professores e alunos "esqueceramnas, e no meu entender todo conhecimento começa pela pergunta. Começa pelo que você, Paulo, chama de curiosidade" (FREIRE; FAUNDEZ, 2002, p. 46). Freire complementa a argumentação de Faundez, afirmando que todo curso de formação inicial de professores deveria, desde o início, incorporar o saber fazer perguntas, alertando que:

[...] o centro da questão não está em fazer com a pergunta "o que é perguntar?" um jogo intelectual, mas viver a pergunta, viver a indagação, viver a curiosidade, testemunhá-la ao estudante. O problema que, na verdade se coloca ao professor é o de, na prática, ir criando com os alunos o hábito, como virtude, de perguntar, de "espantar-se" (FREIRE; FAUNDEZ, 2002, p. 48, grifos nosso).

Nesse sentido, é relevante refletir sobre a formação inicial de professores, pois a postura crítica do educando não mudará se os futuros professores não estiverem preparados para exercerem uma prática pedagógica alicerçada na pergunta. Não podemos esquecer que os professores em formação, quando vão para a escola, acabam encontrando muitas dificuldades para provocar mudanças, uma vez que na universidade são poucos os momentos em que vivenciam um ensino que não seja o tradicional, baseado na pedagogia da resposta. Talvez isso explique a aflição dos futuros professores, quando se preparam para suas primeiras aulas e acabam por demonstrar grande temor na eventualidade de não saberem alguma resposta no decorrer das aulas que serão ministradas por eles.

Carvalho e Gil-Pérez (2001) ressaltam a importância dos professores vivenciarem, ainda no processo de formação, projetos alternativos ao ensino tradicional 
para que possam ter referências quando formados. Isto quer dizer que os professores formadores devem promover tais condições, como afirma Freire (2009, p. 90):

[...] É interessante observar que a minha experiência discente é fundamental para a prática docente que terei amanhã ou que estou tendo agora simultaneamente com aquela. É vivendo criticamente a minha liberdade de aluno ou aluna que, em grande parte, me preparo para assumir ou refazer o exercício de minha autoridade de professor. Para isso, como aluno de hoje que sonha com ensinar amanhã ou como aluno que já ensina hoje devo ter como objeto de minha curiosidade as experiências que venho tendo com professores vários e as minha própria, se as tenho, com meus alunos.

Tais discussões são importantes, pois, embora os estudos indiquem as necessidades apontadas anteriormente, é sabido que os alunos chegam à universidade com uma concepção formada sobre "o ser professor" oriunda de uma formação alicerçada no que Freire (1983) chama de educação bancária, o professor possui os conhecimentos e os transmite na forma de um monólogo aos alunos que, para terem uma boa aprendizagem, basta que sejam capazes de ouvir o discurso do professor e guardar a máxima quantidade de informações possíveis.

Em contraposição à educação bancária, Freire (1983) discute a necessidade do educando ser inserido como sujeito no processo de ensino e aprendizagem, interagindo com o educador em relações dialogais. Nessa perspectiva, o processo de ensino e aprendizagem pode se dar nos dois sentidos, ou seja, o educando aprende com o educador e este aprende com o educando, sendo o diálogo entre ambos a matriz condutora.

Freire (2009) aborda vários ingredientes pertinentes ao campo de atuação do professor tais como a postura, a práxis, a ideologia e outras reflexões sobre o ser professor, discutindo alguns dos saberes necessários à formação de um professor progressista com prática educativa e crítica, argumentando:

[...] que o formando, desde o princípio mesmo de sua experiência formadora, assumindo-se como sujeito também da produção do saber, se convença definitivamente de que ensinar não é transferir conhecimento, mas criar as possibilidades para a sua produção ou a sua construção (FREIRE, 2009, p.22).

A partir das discussões desenvolvidas por Freire (2009), consideramos importante refletir sobre o processo de formação de professores no sentido de pensar a práxis como um processo dialético: formador-formando e formando-formador também como uma via de mão dupla. 
O futuro professor, desde o início da sua formação deve, então, romper com a visão tradicional que sugere o formador como sujeito do processo e o formando como objeto que será formado, devendo ficar claro que "embora diferentes entre si, quem forma se forma e re-forma ao formar e quem é formado forma-se e forma ao ser formado [...]"(FREIRE, 2009, p. 23). Assim, ensinar no processo de formação do formador não é um processo de transferência de conhecimentos, mas antes um caminho onde quem ensina aprende da mesma forma que quem aprende ensina, não sendo possível desenvolver-se a docência sem a discência.

Entre os vários saberes necessários à formação docente apontados em Pedagogia da autonomia, também destacamos a importância do licenciando compreender que "saber é criar as possibilidades para a sua própria produção ou a sua construção e ensinar não é transferir conhecimento” (FREIRE, 2009, p. 47), o que exige do futuro professor a abertura ao diálogo, às perguntas dos alunos, assim como a capacidade de despertar a própria curiosidade e a dos alunos também.

Neste contexto, é importante ao futuro professor saber que "ensinar exige curiosidade", e o professor também precisa saber que o aprender deve provocar no educando uma curiosidade crescente de tal forma a torná-lo criador e responsável pela construção dos conhecimentos (FREIRE, 2009). O ensinar e o aprender estão diretamente relacionados à curiosidade e ao seu movimento em direção à curiosidade epistemológica e a sistematização do saber.

Se o professor não aprende a problematizar a curiosidade, ela pode se transformar no que Freire chama de curiosidade domesticada que no máximo "alcança a memorização mecânica do perfil deste ou daquele objeto" (FREIRE, 2009, p. 85), como ocorre em uma prática de ensino centrada na pedagogia da resposta. Por isso a necessidade de o professor saber, desde o início da sua formação:

Estimular a pergunta, a reflexão crítica sobre a própria pergunta, o que se pretende com esta ou com aquela pergunta em lugar da passividade em face das explicações discursivas do professor, espécies de respostas a perguntas que não foram feitas (FREIRE, 2009, p. 86).

Como a curiosidade também é tema constante na obra de Monteiro Lobato, acreditamos que ela pode ser um dos principais pontos de interseção entre o escritor e Paulo Freire, sendo sua obra infantil uma potencial fonte geradora de discussões a respeito de uma prática pedagógica problematizadora e dialógica. As personagens do Sítio, em particular Dona Benta, que simboliza a professora, e seus netos, apresentam características que vão ao encontro dos pressupostos de uma pedagogia da pergunta 
FORMAÇÃO DE PROFESSORES E ENSINO DE QUÍMICA...

onde "o que importa é que professores e alunos se assumam epistemologicamente curiosos” (FREIRE, 2009, p. 86).

\section{O que nos diz Monteiro Lobato?}

Nos livros da obra infantil, a personagem Dona Benta nos apresenta a ciência em situações condizentes ao ensino das diferentes disciplinas inseridas no contexto escolar da época, revelando o escritor com veia pedagógica e os seus principais ideais didáticos e pedagógicos, sem perder de vista a magia inerente ao texto literário, como destaca Cavalheiro (1956a, p. 171):

[...] O segredo de Lobato estaria, assim, nos atrativos que, como nenhum outro, sabe colocar no meio desse caminho. Neste sentido os livros educativos, como "Emília no País da Gramática", "O Poço do Visconde", "Aritmética da Emília", "História das Invenções", "História do Mundo para Crianças", ou "Geografia de Dona Benta", são exemplos bem ilustrativos.

O livro Serões de Dona Benta apresenta conteúdos relacionados ao ensino da física, da química, da astronomia e um pouco da geologia como podemos notar em alguns dos tópicos indicados no índice desse livro: II - $O$ ar; V - A água; VIII - A matéria; X - As máquinas; XI - A energia do calor; XII - O fogo; XIV - Ventos e Tempestades; XV - Tempo e clima; XVI - Na imensidão do espaço; XVII - O nosso sistema solar; XIX - Como a Terra se formou; XX - O solo e XXI - Riqueza do subsolo.

Nos Serões, é possível encontrar episódios que mostram Dona Benta ensinando e provocando o gosto pelo saber e pelo aprender por meio de abordagens problematizadoras e dialógicas que alicerçam o projeto pedagógico do escritor. Consideramos esse livro um bom exemplo para refletirmos sobre como Dona Benta estabelece o diálogo com os seus netos e a forma como problematiza a curiosidade ingênua e provoca a curiosidade epistemológica na busca pelo saber.

Nossa leitura da obra infantil de Monteiro Lobato permitiu identificar algumas contribuições úteis para o ensino da química. O diálogo e a problematização como forma de permitir que as crianças expressem suas opiniões e dúvidas a respeito dos temas em discussão é sempre uma estratégia adotada para a construção do conhecimento em torno da temática. Como no caso da discussão presente nos Serões de Dona Benta sobre o oxigênio, Narizinho pergunta a Dona Benta: "- Mas como é oxigênio - que cor, que gosto tem? - indagou a menina" (LOBATO, 1957, p. 17). A fala de Narizinho simboliza dúvidas que normalmente são apresentadas pelos alunos, 
quando iniciam a aprendizagem em química e/ou ciências, no entanto, elas só aparecem se houver espaço para o diálogo e a expressão das mesmas.

Dona Benta recorre ao uso da experimentação para responder à indagação de Narizinho e à discussão de questões que surgem através dos resultados verificados com o experimento proposto. $\mathrm{O}$ experimento é fundamental para o entendimento das noções sobre o oxigênio e suas propriedades.

Narizinho saiu correndo e voltou com seis pastilhas de clorato de potássio. Dona Benta tomou-as e disse:

- É muito fácil extrair o oxigênio que há nestas pastilhas mas só no laboratório. Vamos para lá.

Dona Benta havia transformado o antigo quarto de hóspedes em laboratório. Tinha lá uma porção de frascos de drogas, e tubos de vidro, e cubas, e lamparinas de álcool. Um perfeito gabinete científico de amador.

- Bom - disse ela no laboratório. Temos de misturar três partes destas pastilhas com uma parte de dióxido de manganês. Veja aí o vidrinho de dióxido, Pedrinho - esse acolá, na prateleira de cima.

O menino trouxe o vidro de dióxido e Dona Benta fez a mistura dentro dum tubo de vidro fechado numa das pontas e arrolhado na outra. Nessa rolha fez um buraco, onde enfiou outro tubo de vidro mais fino, em forma de S. A perna de cima do S ficava na rolha, e a perna de baixo ia sair dentro dum vidro de boca larga, emborcado numa cuba cheia d'água. Arrumadas as coisas assim, ela acendeu uma lâmpada de álcool e aqueceu o tubo com a mistura de clorato e dióxido. Imediatamente começaram a sair bolinhas, que desciam pelo $\mathrm{S}$ e subiam pela água do vidro de boca larga, indo depositar-se no alto. E a medida que essas bolinhas entravam, a água do vidrão ia descendo. Quando não houve mais bolinhas, Dona Benta fechou o vidro com uma lâmina e o retirou da cuba, pondo-o sobre a mesa, na posição normal. (LOBATO, 1957, p. 17-18)

Dona Benta, para o mesmo experimento introduz a possibilidade do diálogo e o direito à expressão de dúvidas ${ }^{5}$, aparentemente ingênuas ou óbvias, mas de fundamental importância no processo de construção das noções sobre o oxigênio. De acordo com a avó, na extração do oxigênio, utilizam-se duas substâncias no processo: clorato de potássio $\left(\mathrm{KClO}_{3}\right)$ e dióxido de manganês $\left(\mathrm{MnO}_{2}\right)$. Dona Benta afirma que apesar de as duas substâncias apresentarem oxigênio na constituição, "neste caso é só oxigênio do clorato que se desprende em bolinhas. O dióxido não muda" (LOBATO, 1957, p. 18). O escritor problematiza a situação por meio da indagação de Pedrinho que questiona: “Então por que botá-lo junto com o outro?” (LOBATO, 1957, p. 19).

Dona Benta responde: “- Mistérios da Natureza meu filho”, concordando com o neto, mas explicando que o dióxido de manganês age como um catalisador e tem a função de permitir que o oxigênio se desprenda mais rapidamente do "clorato". Se fosse

\footnotetext{
5 Na maioria das vezes não é Dona Benta que faz as perguntas, mas é ela quem possibilita a concretização da dimensão dialógica do processo de ensino e aprendizagem dos netos, possibilitando a expressão das dúvidas e dos questionamentos dos mesmos. Suas respostas ou reflexões provocam o pensar e suas ações sempre respeitam e dialogam com a fala dos netos.
} 
uma aula de química, Dona Benta poderia continuar problematizando, perguntando a Pedrinho porque o clorato de potássio libera o oxigênio e não o dióxido de manganês, mas isso exigiria um nível maior de compreensão, não compatível com o estágio cognitivo das crianças. Neste momento, bastava saber que algumas substâncias atuam como catalisadores com o objetivo de aumentar a rapidez de transformações químicas.

Pedrinho apresenta uma das características que Freire (2009) aponta como essencial para manter o interesse na busca pelo conhecimento, ou seja, uma curiosidade nunca satisfeita. Tal característica permite que o menino comece a romper com o conhecimento do senso comum a respeito do oxigênio, processo esse que caracteriza a curiosidade a caminho de um questionamento epistemológico.

A curiosidade de Pedrinho e seus questionamentos continuam e não satisfeito com as explicações sobre os resultados experimentais observados, faz nova indagação: “- Não percebo nada, vovó - disse ele. O tal oxigênio é um ar à-toa, sem cor, nem cheiro. Como a senhora sabe que o que está no vidro é oxigênio e não ar?" (LOBATO, 1957, p. 19). Tal episódio mostra que a curiosidade já não é tão ingênua assim, mas algo mais complexa que exige a sistematização de conhecimentos para uma compreensão dos fenômenos observados, assemelhando-se à passagem da curiosidade ingênua para a curiosidade epistemológica.

Em situações de ensino onde prevalece o que Freire e Faundez (2002) chamam de educação da resposta com ênfase na memorização mecânica de conteúdos e não na construção de conhecimentos significativos aos educandos, não haveria espaço para perguntas como as feitas por Pedrinho, ou melhor, as indagações até poderiam surgir, mas não seriam externalizadas e, consequentemente, não seriam problematizadas.

Dona Benta, para responder à questão levantada pelo neto e mostrar que o gás produzido era realmente o oxigênio, novamente recorre ao experimento e à discussão lógica dos resultados que também, em uma situação de ensino de química, poderia ser problematizada com reflexões sobre o que significa estar provado em ciência. Bastariam os resultados apresentados para provar que o "ar" do vidro era oxigênio?

- Pelas reações que vamos promover - respondeu Dona Benta. O oxigênio por exemplo, não é combustível - mas sim alimentador do fogo. Sem ele não há fogo, ou combustão. Ponha dentro do vidro uma brasinha de fósforo para ver o que acontece.

O menino riscou um fósforo, deixou formar-se a brasa e apagou a chama. Em seguida lançou-a dentro do vidro de oxigênio. Imediatamente a brasinha virou labareda amarelada, grande.

- Experimente agora com uma ponta de arame bem aquecida.

Pedrinho aqueceu na lâmpada de álcool a ponta dum arame e a enfiou no frasco. Surgiu a mesma chama amarela, com faiscamentos. 


\begin{abstract}
- Está provado que o "ar" do vidro é oxigênio, porque o ar comum não faz isso. $\quad \mathrm{O}$ que houve foi o que os químicos chamam oxidação. $\mathrm{O}$ carbono da brasinha e a ponta do arame oxidaram-se pela ação do grande oxidador que é o oxigênio. Este fenômeno da oxidação é um dos mais importantes que há na natureza, como havemos de ver. Tudo se oxida na presença do oxigênio, umas coisas lentamente, outras rapidamente. Um exemplo de oxidação rápida temos na explosão da pólvora. (LOBATO, 1957, p. 19-20)
\end{abstract}

Entendemos que se trata de um exemplo que ilustra a importância do diálogo, da pergunta e da problematização nas ações pedagógicas do professor, em concordância com Freire (1997, p. 61), quando afirma que “o diálogo pedagógico implica tanto o conteúdo ou objeto cognoscível em torno de que gira quanto a exposição sobre ele feita pelo educador ou educadora para os educandos" e Dona Benta demonstra tal atitude em suas explicações expositivas.

Como já discutimos antes, Freire (2009) afirma que é necessário ao professor, desde o início da sua formação, compreender que formar transcende o objetivo de treinar pessoas como é feito em uma prática de educação bancária. Ao contrário, em uma prática educativa crítica, o professor deve saber que formar o indivíduo envolve a problematização do seu mundo, como um "ser que está sendo", que está inserido em um futuro problemático e histórico, portanto, sujeito a ser construído pelos indivíduos que dele participam.

A sistematização rigorosa das noções de oxigênio e oxidação vai sendo retomada em outros assuntos ao longo dos Serões. O amadurecimento conceitual dos netos é notado nas intervenções que Pedrinho faz, por exemplo, na discussão a respeito do fogo, onde o menino de início avisa que sabe explicar o fenômeno por meio das noções de oxidação e combustão nas quais o oxigênio tem papel fundamental. O caminho que Dona Benta proporciona está de acordo com uma aproximação cada vez mais rigorosa do objeto cognoscível, no caso o oxigênio, aumentando a possibilidade de uma maior "exatidão no conhecimento produzido ou no achado de nossa busca epistemológica" (FREIRE; FAUNDEZ, 2002, p.78), conforme procuramos representar na Figura 1.

Assim, formar não deve ser treinar, ao mesmo tempo em que ensinar não deve ser sinônimo de transferência de conteúdos, mas antes um processo de construção de saberes que possam ser significativos para os educandos. Dona Benta parece incorporar esses saberes em sua prática educativa, uma vez que sempre promove uma pedagogia da pergunta junto aos seus netos, como foi possível discutir por meio da abordagem que a avó professora faz a respeito da noção de oxigênio em Os Serões de Dona Benta. 


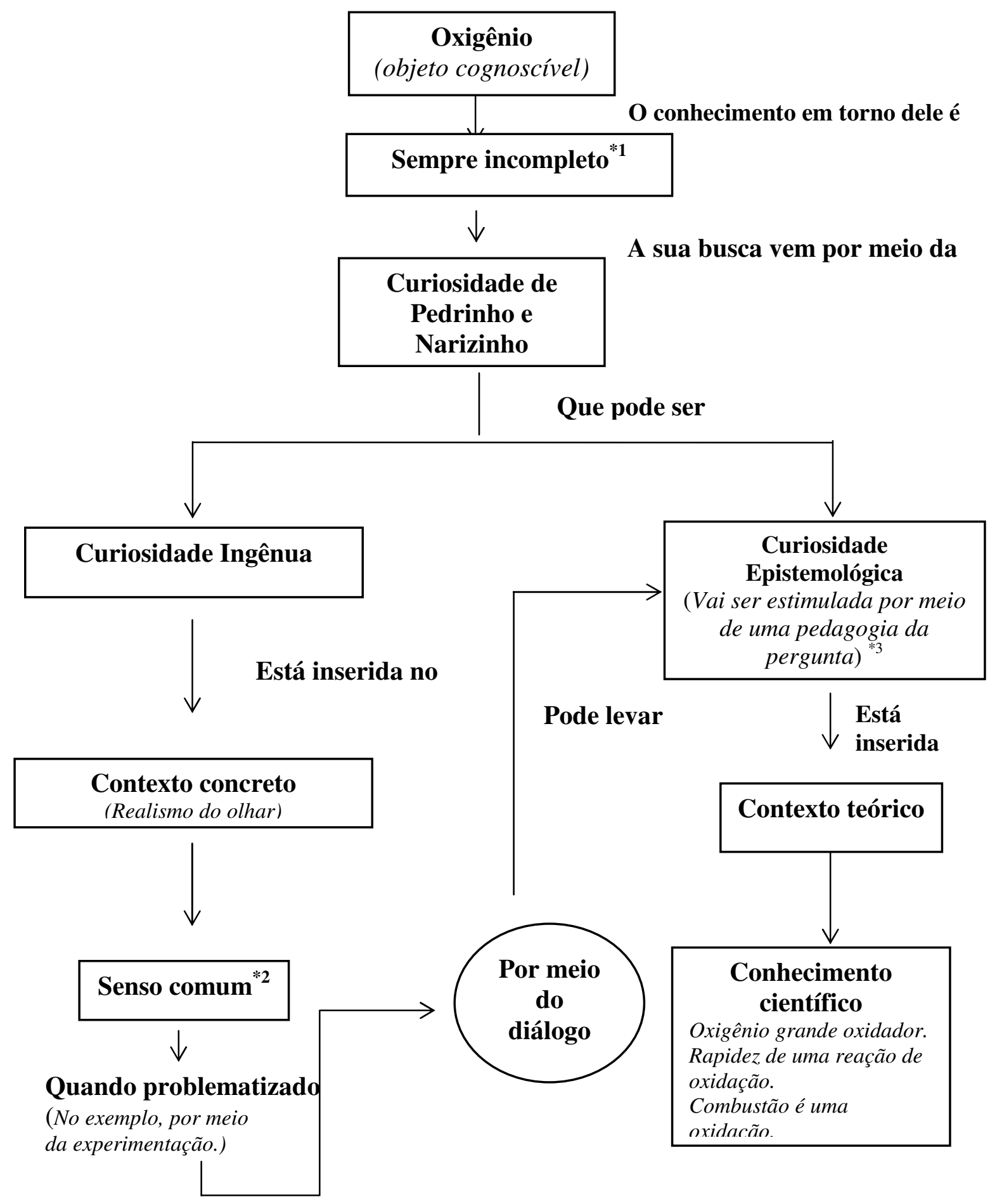

*1 - Tanto que podemos perceber ao longo do livro, em diferentes temáticas, a retomada da noção de oxigênio, mostrando certa evolução desse conceito.

*2 - Realismo do olhar: cor, gosto, sabor.

*3 - Perguntas como: "Então, porque botá-lo (Clorato de potássio) junto com outro?”; Não percebo nada, vovó - disse ele. O tal oxigênio é um ar à-toa, sem cor, nem cheiro. Como a senhora sabe que o que está no vidro é oxigênio e não ar?"

Figura 1: Representação sobre a noção de oxigênio.

Fonte: Autores. 
Também é possível notar a contextualização como possibilidade de problematizar temáticas na tentativa de compreender questões de caráter significativo no contexto dos alunos, como no episódio em que Dona Benta introduz a discussão sobre a água nos Serões de Dona Benta:

Depois do ar Dona Benta falou da água, começando com esta pergunta:

- Que é água?

Todos sabiam. Quem não sabe o que é água?

- Uma coisa que a gente bebe - disse Emília.

- A mãe da vida - respondeu Pedrinho, que era mais filosófico.

- A leva-e-traz - sugeriu Narizinho, lembrando-se do trabalho da água na erosão da terra (O Poço do Visconde.)

Dona Benta explicou:

- A água é um berço onde nascemos e o berço onde ainda se embalam todos os organismos. Sem água não há vida possível, e pois é ela a mãe da vida, como disse Pedrinho. Também é a leva-e-traz, como disse Narizinho. E também uma coisa que a gente bebe, como disse Emília. Fora o homem, todos os seres sejam animais ou vegetais, se utilizam da água para beber apenas.

- E também tomar banho - advertiu Emília. Os passarinhos gostam muito de banhos.

- Sim, banho de refrescar o corpo - concordou Dona Benta, porque os animais se limitam a molhar-se - não se lavam à nossa moda, esfregando o corpo com sabão... ou caco de telha, como fez Emília depois do banho de petróleo. Entre todos os seres só o homem ampliou a utilização da água, escravizando-a às suas necessidades. Transforma-a em vapor, para aproveitar a energia do vapor d'água. Transforma-a em gelo. Utiliza-se das quedas d'água para produzir força mecânica e sobretudo elétrica. Não tem conta os serviços que a água presta ao homem - e felizmente possuímos água na maior abundância.

- Apesar disso, muita gente morre de sede nos desertos e nas secas disse Pedrinho. (LOBATO, 1957, p. 31-32)

O diálogo é conduzido com Dona Benta que respeita a participação e aceita as respostas aparentemente óbvias, como: coisa que a gente bebe, água é um solvente (a leva-e-traz) e serve para tomar banho. O objetivo de Dona Benta é ensinar água do ponto de vista químico, mas nem por isso interrompe as crianças quando expressam o que sabem. Em meio à discussão, a avó aproveita para introduzir a ideia da água como um recurso para a sobrevivência do Homem, expressando a visão da ciência como forma de poder e controle sobre a natureza e os seus recursos ("o homem ampliou a utilização da água, escravizando-a às suas necessidades"). Pedrinho não deixa de expressar o caráter social do uso da água, apontando a existência de muitas pessoas que morrem por não terem acesso à água, problema comum na região dos grandes sertões do país.

Os temas científicos são abordados, mas Monteiro Lobato não deixa de dar asas à imaginação e ao devaneio sobre um futuro ainda por vir. Um exemplo é a discussão que segue sobre a água e as hipóteses a respeito do que aconteceria se as terras abaixo 
do mar se nivelassem com as acima do mar. Narizinho afirma que seria o fim da humanidade, mas Pedrinho demonstra a crença na ciência como caminho para resolver os problemas: “- Isso não - protestou Pedrinho. O homem saberá adaptar-se à água, construindo cidades flutuantes, como os navios de hoje são hotéis flutuantes" (LOBATO, 1957, p. 32).

A fala de Pedrinho expressa o direito de sonhar do escritor com veia científica e sua capacidade de pensar a ciência de seu tempo e os avanços que essa pode conduzir para futuros ainda não imagináveis. No caso das cidades flutuantes, atualmente são vários os projetos como podemos verificar em notícias publicadas na mídia eletrônica:

$\mathrm{O}$ arquiteto belga Vicent Callebault criou um projeto de uma construção que pode ser a solução para a possibilidade da devastação de cidades costeiras com a elevação dos níveis dos oceanos: cidades flutuantes e autossuficientes, capazes de abrigar até 50 mil pessoas.

Essa "ecópolis" teria duas camadas de revestimento, sendo uma delas de fibras de poliéster e a segunda de titânio, que ajudariam a absorver a poluição do ar em um mecanismo ativado por radiação ultravioleta ${ }^{6}$.

Em uma prática pedagógica bancária as discussões poderiam ser interrompidas pelo fato de terem fugido da relação de conteúdos contidos no planejamento pedagógico. A educação nesses moldes é burocratizada nos espaços de tempo disponibilizados para certos assuntos, mesmo que para isso seja necessário desconsiderar o interesse dos alunos. Não é o que faz Dona Benta, uma vez que a avó professora considera a imaginação das crianças como hipóteses passíveis de serem confirmadas em um futuro.

A temática sobre a água também fornece bons exemplos a respeito de como problematizar situações de ensino e a forma como se estabelece o diálogo entre Dona Benta e seus netos, como no episódio da água destilada:

- E que quer dizer água destilada?

- Quer dizer água obtida diretamente da condensação do vapor d'água. A água de chuva é água destilada; a dos rios não é.

- Como não é, se provém do vapor que se condensa em nuvens?

Dona Benta ficava tonta com certas perguntas; mas respondeu que rigorosamente toda água provinha da destilação, mas que na prática tinha o nome de água destilada só a que era obtida no momento, fresquinha, sem que tivesse tempo de dissolver coisas pelo caminho. A água da chuva, por exemplo, não é considerada destilada porque na vinda das nuvens até à terra pode dissolver coisas que existem no ar.

- Então a senhora errou dizendo que água de chuva era água destilada.

\footnotetext{
6 Matéria completa disponível na seção de arquitetura, publicada no dia 30/01/2011 em: http://revistapegn.globo.com/Revista/Common/0,EMI206591-17180,00-

ARQUITETO+BELGA+CRIA+PROJETO+DE+CIDADE+FLUTUANTE+PARA+REFUGIADOS+DE+DESASTR .html - acesso em 08/10/20011.
} 
- Errei e não errei meu filho, porque destilada ela é; mas para usos práticos, de farmácia e outros, só se considera água destilada a que se obtém da condensação do vapor num vaso fechado onde não possa contaminar-se com coisa nenhuma. Est modus in rebus, como diz o latim. (LOBATO, 1957, p. 37)

A discussão sobre o que seria água destilada é um belo exemplo com o qual, mais uma vez, arriscamos uma aproximação com Paulo Freire e os saberes necessários à formação de um professor. Dona Benta demonstra humildade e respeito aos questionamentos dos netos, características estas fundamentais a um professor com prática dialógica. Os netos deixaram a avó tonta de tantas perguntas e argumentos em torno da defesa da água da chuva como água destilada, demonstrando aprendizagem e criticidade em torno do objeto de conhecimento, levando Dona Benta a reconhecer que tinha errado.

Tal episódio reforça a preocupação de Monteiro Lobato em formar crianças críticas e não conformadas com o conhecimento sem questionamentos. Essa é uma característica importante na relação educador-educando, pois em uma prática de educação bancária quase nunca o mestre assume que pode se equivocar. Na contramão, Lobato rompe com a ideia do professor visto como alguém que sabe tudo e não tem o direito de equivocar-se, mostrando a necessidade de o professor ser humilde e aceitar o erro, pois só assim é possível estabelecer um verdadeiro diálogo entre educador e educando.

Freire (1983) discute alguns aspectos que considera fundamentais para a garantia do diálogo, argumentando: "Como posso dialogar, se alieno a ignorância, isto é, se a vejo sempre no outro, nunca em mim? (...) se me fecho à contribuição dos outros, que jamais reconheço, e até me sinto ofendido com ela? (...) se temo a superação e se, só em pensar nela, sofro e definho?" (FREIRE, 1983, p. 94-95). Dona Benta demonstrou em vários momentos as virtudes de saber escutar, aceitar a opinião dos netos, ser humilde, respeitar os conhecimentos dos outros, entre outras características que a colocam como um exemplo de professora que mantém uma proposta dialógica de ensino.

\section{Considerações finais}

Acreditamos que a obra de Monteiro Lobato revela alguns elementos que respondem a questões propostas, por exemplo, a tendência dos escritores com veia científica apresentarem em suas obras características relacionadas à humanização da 
FORMAÇÃO DE PROFESSORES E ENSINO DE QUÍMICA...

ciência, no sentido de incorporar nas estórias, a ciência por meio da fala e ação de personagens inseridos em contextos que revelam aspectos não visíveis nos textos específicos de ciência.

Identificamos em Dona Benta características que Freire (2009) apresenta como saberes necessários para a formação de um professor coerente com uma prática educativa e crítica. A avó professora deixa evidente que formar não é treinar; ensinar não é apenas transferir conteúdos; o saber é sempre incompleto, por isso, a possibilidade de sistematizar melhor aquilo que sabemos; a virtude de saber ouvir e respeitar os saberes do outro; a humildade em reconhecer que não se sabe tudo e é possível aprender com o outro - um exemplo de relação educador-educando - e o diálogo e a problematização da dúvida e da curiosidade como opção metodológica.

De uma forma geral, os conteúdos químicos são inseridos por meio da problematização da curiosidade dos netos que é realizada a partir do diálogo com Dona Benta e o objeto de conhecimento. O diálogo é sustentado pela dúvida, pela pergunta, pela tentativa de resolver um problema e pela busca insaciável do saber apresentada pelos netos, nunca totalmente satisfeitos com as respostas. Fica evidente a possibilidade de olhar a abordagem metodológica de Dona Benta que parte das noções oriundas da curiosidade ingênua e evolui sistematicamente no decorrer dos assuntos abordados nos Serões, como é o caso do oxigênio, rumo à curiosidade epistemológica.

Os netos de Dona Benta não são apenas treinados a memorizarem conteúdos químicos ou científicos. Existe a preocupação com a compreensão dos significados conceituais, tanto que oxigênio, água, calor e hipótese são noções que aparecem em diferentes assuntos, sempre com a possibilidade de retomada daquilo que já foi discutido e o amadurecimento conceitual vai ocorrendo conforme o processo que Freire e Faundez (2002) denominam como a possibilidade de sistematizar teoricamente cada vez mais o objeto de conhecimento.

Certamente não esgotamos as possibilidades de leitura a respeito das interações entre ciência e literatura na obra do escritor Monteiro Lobato, nem poderíamos, face à pluralidade de sentidos que o texto literário traz para o leitor. A pesquisa forneceu elementos para estabelecer a ponte entre química e literatura na formação de licenciandos em química porque aponta o potencial do livro para discutir questões pedagógicas.

Os Serões de Dona Benta podem ser utilizados para problematizar o significado de situações de ensino centradas no diálogo, na problematização e na pedagogia da 
pergunta no contexto das disciplinas pedagógicas da Licenciatura em Química, por exemplo, no Estágio Supervisionado como uma alternativa de texto para inserir a leitura no contexto da formação inicial e promover discussões que permitam aos licenciandos à construção de significados a respeito do papel da curiosidade e da pergunta em processos de ensino e aprendizagem.

\section{Referências}

ALMEIDA, M. J.P.M. de; SILVA, H. C (Org.). Linguagens, leituras e Ensino da Ciência, Campinas: Mercado das Letras, 1998.

ALVAREZ, R. V. Monteiro Lobato, escritor e pedagogo, Rio de Janeiro: Edições Antares; Brasília: INL, 1982.

APÓSTOLO NETTO, J. O discurso cientificista no livro "A Chave do Tamanho" de Monteiro Lobato, Pós-História, Assis, n. 4, 1996.

ARAPIRACA, M A. Prólogo de uma Paidéia Lobatiana fundada no fazer lúdico e especulativo: A chave do tamanho. Tese de Doutorado - Universidade Federal da Bahia, Salvador, 1996.

BRASIL. Parecer CNE/CES 1.303/2001, de 06 de novembro de 2001. Diretrizes Curriculares Nacionais para os Cursos de Química Diretrizes Curriculares Nacionais para os Cursos de Química. Diário Oficial da União, Brasília, seção 1, pt.1, p. 6009, 07 de dezembro de 2001.

CAMENIETZKI, C. Z. O Saber Imponente: estudo da noção de ciência na obra infantil de Monteiro Lobato,1988. Dissertação de Mestrado - FGV: Rio de Janeiro.

CARDOSO, R.D. Geografia de Dona Benta: o mundo pelos olhos da imaginação. In: LAJOLO, M.; CECCANTINI, J.L. (Org.). Monteiro Lobato Livro a Livro: obra infantil, São Paulo: Editora UNESP: Impressa Oficial do Estado de São Paulo, 2008.

CARVALHO, A.M.P. de; GIL-PÉREZ, D. Formação de Professores de Ciências: tendências e inovações. São Paulo: Cortez, 2001.

CARVALHO, F. A. de. Outros... Com textos e passagens: traços biológicos em obras de Monteiro Lobato, 2002. Dissertação de Mestrado - Unicamp: Campinas.

CATINARI, A.F. Monteiro Lobato e o projeto de educação interdisciplinar. Dissertação de Mestrado - Universidade Federal do Rio de Janeiro: Rio de Janeiro, 2006.

CAVALHEIRO, E. Monteiro Lobato: Vida e Obra - Tomo I. São Paulo: Companhia Editora Nacional, 1956a.

CAVALHEIRO, E. Monteiro Lobato: Vida e obra - Tomo II, São Paulo: Companhia Editora Nacional, $1956 b$. 
FORMAÇÃO DE PROFESSORES E ENSINO DE QUÍMICA...

DUARTE, L.C. Serões: verdades científicas ou comichões lobatianas? In LAJOLO, M.; CECCANTINI, J.L. (Org.). Monteiro Lobato Livro a Livro: obra infantil, São Paulo: Editora UNESP: Impressa Oficial do Estado de São Paulo, 2008.

FREIRE, P. Pedagogia do Oprimido. $13^{\mathrm{a}}$ ed. Rio de Janeiro: Paz e Terra, 1983.

FREIRE, P. Pedagogia da Esperança: um reencontro com a Pedagogia do Oprimido, Rio de Janeiro: Paz e Terra, 1997.

FREIRE, P.; FAUNDEZ, A. Por uma pedagogia da pergunta, Rio de Janeiro: Editora Paz e Terra, $5^{\text {a }}$ edição, 2002.

FREIRE, P. Pedagogia da Autonomia: saberes necessários à prática educativa, São Paulo: Paz e Terra, 39 edição, 2009.

GONÇALVES, F.P. Experimentação e Literatura: Contribuições para a Formação de Professores de Química, Química Nova na Escola, v. 36, n. 2, p. 93-100, 2014.

GROTO, S.R. Literatura de Monteiro Lobato no Ensino de Ciências. Dissertação de Mestrado, Natal, Universidade Federal do Rio Grande do Norte, 2012.

GROTO, S.R.; MARTINS, A.F.P. Monteiro Lobato em aulas de ciências: aproximando ciência e literatura na educação científica, Ciência \& Educação, v. 21, n.1, p. 219-238, 2015a.

GROTO, S.R.; MARTINS, A.F.P. A Literatura de Monteiro Lobato na Discussão de Questões acerca da Natureza da Ciência no Ensino Fundamental. Ensaio - Pesquisa em Educação em Ciências, v.17, n.2, p. 390-413, 2015 b.

LAJOLO, M.; CECCANTINI, J.L. (Org.). Monteiro Lobato Livro a Livro: obra infantil, São Paulo: Editora UNESP: Impressa Oficial do Estado de São Paulo, 2008.

LOBATO, M. Obras Completas de Monteiro Lobato - Serões de Dona Benta e História das Invenções, São Paulo: Editora Brasiliense, 1957.

MACEDO, V.L.V de. O faz-de-conta de Jean Piaget na literatura de Monteiro Lobato, Belo Horizonte: Cuatiara, 1996.

NUNES, Cassiano. Monteiro Lobato e Anísio Teixeira: o sonho da educação no Brasil, São Paulo: Biblioteca Infantil Monteiro Lobato, 1986.

NUNES, L.A. A literatura infantil de Monteiro Lobato e o ideário escolanovista, Revista de Iniciação Científica da FFC, v.4, n.2, 2004.

OLIVEIRA, L.S. de. A perspectiva científica de Monteiro Lobato na obra $O$ poço do Visconde: um estudo à luz da História da Ciência, Tese de doutorado, São Paulo: Pontifícia Universidade Católica de São Paulo, 2011. 
PEREIRA, R. de B. Memórias do Visconde de Sabugosa, Dissertação de Mestrado, Campinas, Unicamp, 2006.

PINTO NETO, P.C. Ciência, Literatura e Civilidade, Tese de Doutorado Campinas, Unicamp, 2001.

PINTO NETO, P.C. Júlio Verne: o propagandista das ciências, Ciência \& Ensino, n.12, p.10-15, 2004.

PINTO NETO, P. C. A Química Segundo Primo Levi. Anais do XIV Encontro Nacional de Ensino de Química, Curitiba, 2008. Disponível em http://www.quimica.ufpr.br/eduquim/eneq2008/resumos/R0880-1.pdf. Acesso em 21 de agosto de 2009.

PINTO, G.A. Divulgação científica como literatura e o ensino de ciências, São Paulo: FEUSP, 2007. Tese de Doutorado.

PORTO, P.A. Augusto dos Anjos: ciência e poesia, Química Nova na Escola, n.11, p. 30- 34, 2000.

PORTO, P.A.; LAKATOS, V.K.; TIEDEMANN, P.W. Primo Levi and The Periodic Table: Teaching Chemistry using a Literary Text. Journal of Chemical Education, v. 84, n. 5, p.775-778, 2007.

SANTOS, E. da S. Monteiro Lobato e suas seis personagens em busca da nação. Dissertação de Mestrado. UNESP, Marília, 2008.

SANTOS, T. P. dos. Concepções de Ciência nas Obras de Monteiro Lobato: mapeamento e análise de termos científicos no livro Serões de Dona Benta, Bauru: UNESP, 2011. Dissertação de mestrado.

SCAVONE, A. C. Reflexos do Positivismo em A Chave do Tamanho, Letras de Hoje, n. 43, 1981.

SILVA. C. S. da. Poesia de António Gedeão e a formação de professores de química, Química Nova na Escola, v. 33, n. 2, p. 77-84, 2011.

TEIXEIRA LUIZ, F. Aritmética da Emília (1935): matemática para (não) matemáticos? In LAJOLO, M.; CECCANTINI, J.L. (Org.). Monteiro Lobato Livro a Livro: obra infantil., São Paulo: Editora UNESP: Impressa Oficial do Estado de São Paulo, 2008.

VIANNA, A.; FRAIZ, P. (Orgs.) Conversas entre amigos: correspondência escolhida entre Anísio Teixeira e Monteiro Lobato, Rio de Janeiro: CPDOC; Fundação Cultural da Bahia, 1986.

ZANETIC, J. Literatura e cultura científica. In ALMEIDA, M.J.P.M. de; SILVA, H.C. da (Org.). Linguagens, leituras e ensino da ciência. Campinas: Mercado de Letras: Associação de Leitura do Brasil - ALB, 1998. 
ZANETIC, J. Física e arte: uma ponte entre duas culturas, Pro-Posições, v. 17, n. 1, p. 39-57, 2006.

MARCELO PIMENTEL DA SILVEIRA. Bacharel em Química pela UNESP Araraquara, licenciado em Química pela Faculdade Oswaldo Cruz, mestre e doutor em Ensino de Ciências pela USP, atualmente é professor adjunto e coordenador subprojeto de Química junto ao Programa Institucional de Bolsa de Iniciação à Docência (PIBID) da Universidade Estadual de Maringá (UEM), atuando principalmente com os seguintes temas: formação de professores, experimentação e relações entre ciência e arte, especificamente, química e literatura.

JOÃO ZANETIC. Graduação em Física pelo Instituto de Física da Universidade de São Paulo (IFUSP), mestrado em Física pelo IFUSP, mestrado em Science Education pela Universidade de Londres, doutor em Ensino de Física pela Faculdade de Educação da USP, atualmente é professor sênior (aposentado) do IFUSP. Tem experiência na área de pesquisa em ensino de física, atuando principalmente com os seguintes temas: história da física, epistemologia, física e literatura e cultura científica.

Recebido: 21 de setembro de 2015

Revisado: 23 de fevereiro de 2016

Aceito: 05 de maio de 2016 